\title{
Rapid and Sustained Response to a Single Dose of Sertraline in a Patient with Newly Emergent Depression During Varenicline- Assisted Smoking Cessation
}

\section{To the Editor:}

Depression is common during smoking cessation in patients with and without a prior history of depression. 1-4 Depression and other serious neuropsychiatric symptoms have also been reported during varenicline-assisted smoking cessation and the United States Food and Drug Administration has recently required a box warning of this risk. A case report of a severe depressive episode, occurring after initiation of varenicline-assisted smoking cessation in a patient with no prior history of depression who received treatment with sertraline is described.

\section{INTRODUCTION}

Varenicline is the latest smoking cessation medication launched in the US (May 2006). Varenicline is believed to exert its therapeutic effect by binding to neuronal nicotine acetylcholine receptors ( $\mathrm{A} A \mathrm{ChR}$ ) with high affinity and selectivity for the $\alpha 2 \beta 4$ subtype. ${ }^{5}$ Varenicline has a 15-fold higher affinity for this receptor than nicotine and thus successfully blocks nicotine from stimulating the receptor. ${ }^{6}$ However, unlike nicotine which is a full agonist, varenicline is only a partial agonist of the $\alpha 2 \beta 4 \mathrm{nAChR}$ receptor. It is thought that by preventing nicotine from binding to $\alpha 2 \beta 4$ receptors, varenicline attenuates the rewarding effects of smoking, while at the same time sufficiently stimulating the mesolimbic dopamine system to provide blunting of the craving associated with nicotine withdrawal and alleviate the symptoms of withdrawal. ${ }^{7}$

Interestingly, varenicline has also been associated with possible antidepressant effects in preclinical and clinical studies. ${ }^{8,9}$ However, potential adverse neuropsychiatric effects have been reported in association with the use of varenicline. ${ }^{10,11}$ These concerns led to an FDA mandated "boxed warning (7/1/09)" in the varenicline product labeling to alert healthcare professionals to the possibility of "depressed mood, hostility, agitation, and suicidal thoughts or actions". ${ }^{12}$ There have also been several case reports of varenicline exacerbating mood and cognitive disturbances in patients with a history of schizophrenia, depression, bipolar disorder, personality disorder, and substance abuse..$^{13-15}$

The following case report describes a patient who developed acute depression during the course of varenicline treatment and received a single dose of sertraline with a rapid and sustained response while continuing varenicline treatment.

\section{CASE REPORT}

A 39-year-old married Caucasian man, father of three children, had been a smoker for 23 years. $\mathrm{He}$ has two living parents and two younger siblings, a 38-year-old sister and a 35-year-old brother. He described his father as a depressive, pessimistic individual, who had been a lifelong smoker. He described his brother as occasionally moody but with no history of affective disorder or psychiatric treatment.

The patient had made one previous attempt at smoking cessation at 29 years of age. During that period he was largely abstinent from cigarettes for 18 months while still smoking occasionally. He reported no major depression or depressive mood with his prior abstinence. At the start of treatment, he was smoking $\sim 1$ pack 
of cigarettes/day. He described his current response to cigarettes as follows: If he goes too long between cigarettes or he is experiencing a stressful day, he begins to feel irritable, indecisive, and "cloudy minded." He experiences immediate relief upon smoking and "an even keel feeling" ,thus allowing him to think clearly and maintain "a state of calm."

About 9 months ago, contemporaneous with learning of his wife's pregnancy, he decided to quit smoking. He consulted with his general practitioner who prescribed varenciline according to the manufacturer's instructions, to a final dose of $1 \mathrm{mg}$ BID. The patient had no history of psychiatric illness and in particular, no prior episodes of hypomania or affective instability, and was on no other medications prior to starting varenicline.

On the eighth day of varenicline treatment, consistent with his planned "quit date", he stopped smoking completely. During the third week of treatment, he developed severe depressive symptoms including prominent anhedonia, difficulty thinking and concentrating, indecisiveness, and loss of energy. He further experienced a weight gain of 20 pounds and significant sleep disruption with vivid, bizarre dreams and nightmares. He denied suicidal ideation, though he experienced marked feelings of hopelessness, "no sense of the future", and lack of purpose in his life. He said, "I saw no reason to get up in the morning." He had no experience of mood swings, hallucinations, and paranoid or other delusional thinking.

The patient appeared for treatment one week after the onset of this depression. He was adamant in his determination to complete the varenicline treatment so that he could successfully stop smoking. He reported that the varenicline had relieved him of any feelings of craving for cigarettes. In recognition of the depth of the depression, sertraline $25 \mathrm{mg} / \mathrm{day}$ was initiated at that time with the intention of gradually increasing the dose. The patient took the first dose of sertraline in the morning of that day. Within 2 hours he began to experience high energy, lightheadedness, and mild elation. The elation abated by mid-afternoon, but he continued to feel much improved in his mood, concentration, and cognition. At the end of that day, he successfully completed projects at work which he had been delaying for weeks due to his depression.
He described this dramatic transformation as though a light switch had been "turned on in my head." That evening, he told his wife that he began to feel like his "old self" again. His mood was generally euthymic and he reported no further symptoms of anxiety, poor concentration, anhedonia, lethargy, and negativism. He felt that it was unnecessary to continue the sertraline since his depressive symptoms had resolved and remained resolved when he awoke the following morning. In addition, his sleep pattern had returned to normal and he was able to sleep without interruption. This patient continued to remain stable in spite of an additional 2 weeks of varenicline treatment. $\mathrm{He}$ discontinued varenicline at the end of the 8 weeks of treatment. At this time, he has maintained abstinence for 9 months post cessation and has had no further episodes of depression while remaining free of all medications.

\section{DISCUSSION}

This case has possible relevance to two important clinical issues: first, the course of therapeutic action to be undertaken if a patient develops depression while being treated with varenicline for smoking cessation and second, how to augment or accelerate antidepressant response.

There are many people who wish to stop smoking that seem to benefit from the assistance of varenicline, and like this patient, do not wish to stop the varenicline but develop intercurrent major depression. Despite the known health risks of continued smoking, these patients often revert to smoking to avoid the severe mental pain and functional impairment of depression.

The dilemma clinicians currently face lies in the decision of how best to help these patients: Should the varenicline be discontinued in a patient otherwise responding positively to the drug and risk relapse to smoking? Or should it be continued and risk the perdurance and possible worsening of a severe debilitating depression? A recent study by Gunnel and colleagues ${ }^{16}$ analyzed the United Kingdom General Practice Database to compare risk of suicidal behavior, suicidal thoughts, or depression in patients treated with varenicline, nicotine replacement, or buproprion to aid smoking cessation has bearing on this issue. This study found no evidence that varenicline was associated with increased risk of depression or suicidal thoughts. There was also no difference in the mean risk ratio for 
self-harm (vareniciline: 1.12; buproprion: 1.17) However, the possibility of increased risk based on the upper limits of the $95 \%$ confidence interval for both of these drugs (varenicline: 1.88; buproprion: 2.32) could not be ruled out. Thus, the clinician might take some comfort in continuing the smoking cessation treatment, yet the patient remains depressed. This case suggests a possible resolution of this painful dilemma. To our knowledge, this is the first report of a patient with treatment emergent depression successfully treated with an antidepressant without interrupting varenicline treatment.

The specific features of this patient's response may also be informative with regard to a more general strategy for antidepressant augmentation or response acceleration. Although it is quite possible that the patient's response in this case could represent a placebo reaction, if we assume that it represents a genuine pharmacological response, it suggests a possible novel approach to antidepressant augmentation.

The rapid and sustained response this patient demonstrated has support in the preclinical and, albeit sparse, clinical literature.$^{5,8,9}$ Varenicline appears, on the basis of this literature, to have antidepressant properties itself. Among other possibilities, one putative source of the antidepressant effect is related to the anticholinergic hypothesis of antidepressant action. Specifically, it has been shown that reduction in stimulation of $\alpha 2 \beta 4 \mathrm{nAChRs}$ is related to antidepressant action and reciprocally that excessive stimulation of these receptors is related to the pathophysiology of depression. ${ }^{17}$ This proposition also provides one of the hypotheses of the basis of nicotine withdrawal depressions.

Nicotine is a potent stimulator of the $\alpha 2 \beta 4$ $\mathrm{nAchR}$ and chronic use of nicotine leads to desensitization of the receptor. This is thought to be one potential source of nicotine's antidepressant action. ${ }^{18}$ Upon discontinuation of nicotine, these receptors sensitize, particularly in susceptible individuals, and contribute to smoking cessation related depression. Varenicline and the other partial agonists, cytosine and dianicline, have been shown to be potent desensitizers of these receptors. ${ }^{19}$ In addition, varenicline has been shown in several animal models of "behavioral despair" to be significantly effective at reducing inmobility time. Perhaps most saliently for this case, in these "behavioral despair" tests low dose varenicline added to only a moderately effective dose of sertraline produced a maximal efficacy effect equivalent to full dose amitriptyline. ${ }^{20}$

The limited clinical data available also support the hypothesis that varenicline may have antidepressant properties. There have been two relevant studies. Patterson ${ }^{21}$ conducted a double-blind within-subjects crossover study of the effects of smoking cessation on mood in healthy smokers. Over a 3 day period of abstinence there was significantly less negative affect and more positive affect when the subjects were taking varenicline than when they were receiving placebo. In another very interesting open label study, 18 smokers with concomitant treatment -resistant depression had varenicline added as an augmentation agent to their current antidepressant treatment. This group as a whole was reported to show significant improvement in depression measured by the Quick Inventory of Depressive Symptomatology (Self-Report). ${ }^{22}$

Finally, rapid response in major depression has been reported with ketamine, fluoxetine, and other agents in premenstrual syndrome, and sertraline has been shown to have immediate physiological effect on the hypothalamic-pituitary-adrenal axis. ${ }^{23-25}$ This is weakly supportive but convergently consistent with the possibility that the sertralinevarenicline combination may produce an augmented antidepressant effect in some patients.

It is thus conceivable that varenicline rather than inducing depression may actually be reducing nicotine withdrawal depressions. In this particular case, a low dose of sertraline may have produced the strong augmenting effect demonstrated in animal models. The continuation of the varenicline may have then been sufficient to maintain the treatment response and provide the time necessary for stabilizing the patient. This hypothesis does not preclude the possibility that, in certain susceptible individuals, varenicline may be provocative of neuropsychiatric symptoms. In this regard, this patient's response is also informative. The patient reported a very brief period of unusual elation following the administration of the sertraline. This mood effect normalized over just a few hours. It is possible that, had the patient continued with sertraline, he may have converted to a full manic episode. In certain highly susceptible individuals, such as those with a vulnerability to bipolar depression, varenicline's effects may be sufficient to produce such a switch. Such a speculation and illustrative cases have been previously reported. ${ }^{26,27}$ Also, we 
have not in this brief discussion addressed varenicline's effects on the $\alpha 7$ nAChR. Varenicline can also, at higher doses, desensitize this receptor. It is possible that in certain individuals with a latent $\alpha 7$ defect, varenicline may induce a decompensatory process through this mechanism. In summary, although it is difficult to generalize from individual cases, this patient's response suggests that there may be an effective strategy for managing treatment emergent nicotine withdrawal depression during varenicline-assisted smoking cessation without the necessity of discontinuing the varenicline treatment.

\section{Sincerely, \\ Xiaolei Yu Baran, MD \\ John P. Docherty, MD}

\section{REFERENCES}

1. Covey LS, Glassman AH, Stetner F. Major depression following smoking cessation. Am JPSychiatry. 1997:154:263-265

2. Tsoh JY, Humfleet GL, Muñoz RF, Reus VI, Hartz DT, Hall SM. Development of major depression after treatment for smoking cessation. Am J Psychiatry. 2000;157:368-374.

3. Glassman AH. Helzer JE, Covey LS, et al. Smoking, smoking cessation, and major depression. JAMA. 1990;264:1546-1549.

4. Hall SM, Muñoz RF, Reus VI, Sees KL. Nicotine, negative affect, and depression. $J$ Consult Clin Psychol. 1993:61:761-767.

5. Rollema H. Hajós M. Seymour PA, et al. Preclinical pharmacology of the alpha4beta2 nAChR partial agonist varenicline related to effects on reward, mood and cognition. Biochem Pharmacol. 2009;78:813-824.

6. Kasliwal R, Wilton LV, Shakir SA. Safety and drug utilization profile of varenicline as used in general practice in England: interim results from a prescription-event monitoring study. Drug Saf. 2009:32:499-507.

7. Imperato AA, Mulas A, Di Chiara G: Nicotine preferentially stimulates dopamine release in the limbic system of freely moving rats. Eur J Pharmacol. 1986;132:337-338.

8. Grosshans M, Mutschler J, Hermann D, Mann K, Diehl A. Reduced affective symptoms during tobacco dependence treatment with varenicline. Addiction. 2009;104:859-861.
9. Philip NS, Carpenter LL, Tyrka AR, Whiteley LB, Price LH. Varenicline augmentation in depressed smokers: an 8-week, open-label study. J Clin Psychiatry. 2009;70:1026-1031.

10. Popkin MK. Exacerbation of recurrent depression as a result of treatment with varenicline. Am J Psychiatry. 2008:165:774

11. Pirmoradi P, Roshan S, Nadeem SS. Neuropsychiatric disturbance after initiation of varenicline in a patient with a history of alcohol abuse and major depression. Am J Health Syst Pharm. 2008:65:1624-1626.

12. FDA Drug Safety Newsletter. http://www.fda.gov/Drugs/DrugSafety/ PublicHealthAdvisories/ucm169988.htm. Accessed: February 11, 2010.

13. Lyon GJ. Possible varenicline-induced paranoia and irritability in a patient with major depressive disorder, borderline personality disorder, and methamphetamine abuse in remission. J Clin Psychopharmacol. 2008:28:720-721.

14. Pumariega AJ, Nelson R, Rotenberg L. Varenicline-induced mixed mood and psychotic episode in a patient with a past history of depression. CNS Spectr. 2008;13:511-514.

15. Kohen I, Kremen N. Varenicline-induced manic episode in a patient with bipolar disorder. Am J Psychiatry. 2007;164:1269-1270.

16. Gunneil D, Irvine D, Wise L, Davies C, Martin RM. Varenicline and suicidal behaviour: a cohort study based on data from the General Practice Research Database. BMJ. 2009;339:b3805.

17. Foulds $\mathrm{J}$. The neurobiological basis for partial agonist treatment of nicotine dependence: varenicline. Int J Clin Pract. 2006;60:571-576.

18. Andreasen JT, OIsen GM, Wiborg O, Redrobe JP. Antidepressant-fike effects of nicotinic acetylcholine receptor antagonists, but not agonists, in the mouse forced swim and mouse tail suspension tests. J Psychopharmacol. 2009;23:797-804.

19. Rollema H, Coe JW. Chambers LK, Hurst RS, Stahl SM, Williams KE. Rationale, pharmacology and clinical efficacy of partial agonists of alpha4beta2 $\mathrm{nACh}$ receptors for smoking cessation. Trends Pharmacol Sci. 2007;28:316-235.

20. Rollema H, Guanowsky V, Mineur YS, et al. Varenicline has antidepressant-like activity in the forced swim test and augments sertraline's effect. Eur $J$ Pharmacol. 2009:605:114-116.

21. Patterson F, Jepson C, Strasser AA, et al. Varenicline improves mood and cognition during smoking abstinence. Biol Psychiatry. 2009;65:144-149.

22. Philip NS, Carpenter LL, Tyrka AR, Whiteley LB, Price LH. Varenicline augmentation in depressed smokers: an 8-week, open-label study. J Clin Psychiatry. 2009:70:1026-1031.

23. Zarate CA Jr, Singh JB, Carison PJ, et al. A randomized trial of an N-methyl-D-aspartate antagonist in treatment-resistant major depression. Arch Gen Psychiatry. 2006;63:856-864

24. Daamen MJ, Brown WA. Single-dose fluoxetine in management of premenstrual syndrome. J Clin Psychiatry. 1992;53:210-211.

25. Ahrens T, Frankhauser P. Lederbogen F, Deuschle M. Effect of single-dose sertraline on the hypothalamus-pituitary-adrenal system, autonomic nervous system, and platelet function. J Clin Psychopharmacol. 2007:27:602-606.

26. AlhatemF, Black JE. Varenicline-induced mania in a bipolar patient. Clin Neuropharmacol 2009:32:117-118

27. Liu ME, Tsai SJ, Yang ST. Varenicline-induced mixed mood and psychotic episode in a patient with schizoaffective disorder. CNS Spectr. 2009;14:346.

Dr. Baran is assistant professor in the Department of Psychiatry at Weill Cornell Medical College in New York, NY and assistant attending psychiatrist at New York Presbyterian Hospital, Payne Whitney Westchester in White Plains, NY. Dr. Docherty is adjunct professor in the Department of Psychiatry at Weill Cornell Medical College and director of postgraduate education at New York Presbyterian Hospital, Payne Whitney Westchester.

Faculty Disclosures: Dr. Baran does not have an affiliation with or financial interest in any organization that might pose a conflict of interest. Dr. Docherty is a consultant to Bristol-Myers Squibb; and is on the speaker's bureau of and has received honoraria from AstraZeneca, Bristol-Myers Squibb, Johnson \& Johnson, and Merck.

Submitted for publication: August 21, 2009; Accepted for publication: November 20, 2009.

Please direct all correspondence to: Xiaolei Yu Baran, MD, New York Presbyterian Hospital, Payne Whitney Westchester, White Plains, NY 10605; Tel: 914-997-4358, Fax: 646-962-1998; E-mail: xyu@med.cornell.edu. 